\title{
Celiac and perigastric lymph node metastasis of prostate cancer diagnosed with endoscopic ultrasound-guided fine-needle aspiration
}

\author{
Tan Attila MD ${ }^{1}$, Reva Ricketts-Loriaux $\mathrm{DO}^{2}$, David A Sauer $\mathrm{MD}^{2}$, Douglas O Faigel MD ${ }^{1}$
}

\begin{abstract}
T Attila, R Ricketts-Loriaux, DA Sauer, DO Faigel. Celiac and perigastric lymph node metastasis of prostate cancer diagnosed with endoscopic ultrasound-guided fine-needle aspiration. Can J Gastroenterol 2009;23(7):479-480.
\end{abstract}

Endoscopic ultrasound has been used to diagnose and stage gastrointestinal and nongastrointestinal tumours. To our knowledge, the present report describes the first case of celiac and perigastric lymph node metastasis of prostate cancer diagnosed with endoscopic ultrasoundguided fine-needle aspiration.

Key Words: Endoscopic ultrasound; Fine-needle aspiration; Lymph node; Prostate

\section{CASE PRESENTATION}

n 82-year-old Caucasian man presented to his primary - 1 care physician with a $9.1 \mathrm{~kg}$ unintentional weight loss, decreased appetite and new-onset difficulty in voiding. Five years previously, the patient underwent suprapubic prostatectomy for benign prostatic hypertrophy, with no malignancy on transrectal ultrasound biopsies. Initial laboratory results showed abnormal levels of prostate-specific antigen (PSA) $1.57 \mu \mathrm{g} / \mathrm{L}$ (normal less than $0.065 \mu \mathrm{g} / \mathrm{L}$ ), aspartate transaminase $100 \mathrm{U} / \mathrm{L}$ (normal range $5 \mathrm{U} / \mathrm{L}$ to $43 \mathrm{U} / \mathrm{L}$ ), alanine transaminase $82 \mathrm{U} / \mathrm{L}$ (normal $10 \mathrm{U} / \mathrm{L}$ to $58 \mathrm{U} / \mathrm{L}$ ), alkaline phosphatase $577 \mathrm{U} / \mathrm{L}$ (normal range $40 \mathrm{U} / \mathrm{L}$ to $129 \mathrm{U} / \mathrm{L}$ ), total bilirubin $29.07 \mu \mathrm{mol} / \mathrm{L}$ (normal less than $20.52 \mu \mathrm{mol} / \mathrm{L})$ and direct bilirubin $10.06 \mu \mathrm{mol} / \mathrm{L}$ (normal $6.84 \mu \mathrm{mol} / \mathrm{L}$ ). The patient's PSA level three years previously was $0.01 \mu \mathrm{g} / \mathrm{L}$. An abdominal ultrasound showed normal liver parenchyma, intrahepatic biliary ductal dilation with a normal common bile duct (6 $\mathrm{mm}$ in diameter) without any stones or sludge within the biliary tree, a solid peripancreatic mass $(1.6 \mathrm{~cm} \times 2.3 \mathrm{~cm} \times 1.3 \mathrm{~cm}$ in size $)$ and ascites. A subsequent computed tomography (CT) scan showed extensive peripancreatic and retroperitoneal adenopathy $(3.4 \mathrm{~cm}$ in the greatest cross-sectional diameter), a dilated intrahepatic biliary tree and ascites. A transrectal prostate ultrasound and biopsy revealed a prostate adenocarcinoma (Gleason score of $4+5$ out of 9) with perineural involvement but no lymphatic, vascular or extraprostatic invasion. A bone scan revealed multiple, small, focal osteoblastic lesions consistent with metastatic disease. An upper endoscopic ultrasound ([EUS] Olympus GF-UM160 and GF-UC140P, Olympus America Inc, USA) revealed eight hypoechoic, heterogeneous, oval and roundshaped lymph nodes (gastrohepatic, periduodenal, peripancreatic and celiac) (Figure 1). The size of the lymph nodes ranged from $15 \mathrm{~mm}$ to $30 \mathrm{~mm}$. EUS-guided fine-needle

\author{
Métastases d'un cancer de la prostate aux \\ ganglions lymphatiques coliaques et \\ périgastriques diagnostiquées après une \\ aspiration à l'aiguille fine échoguidée
}

L'endoscopie échoguidée a été utilisée pour diagnostiquer et stadifier les tumeurs gastro-intestinales et autres. À notre connaissance, le présent rapport décrit le premier cas de métastases d'un cancer de la prostate propagées aux ganglions lymphatiques cœliaques et périgastriques diagnostiqué par aspiration à l'aiguille fine lors d'une endoscopie échoguidée.

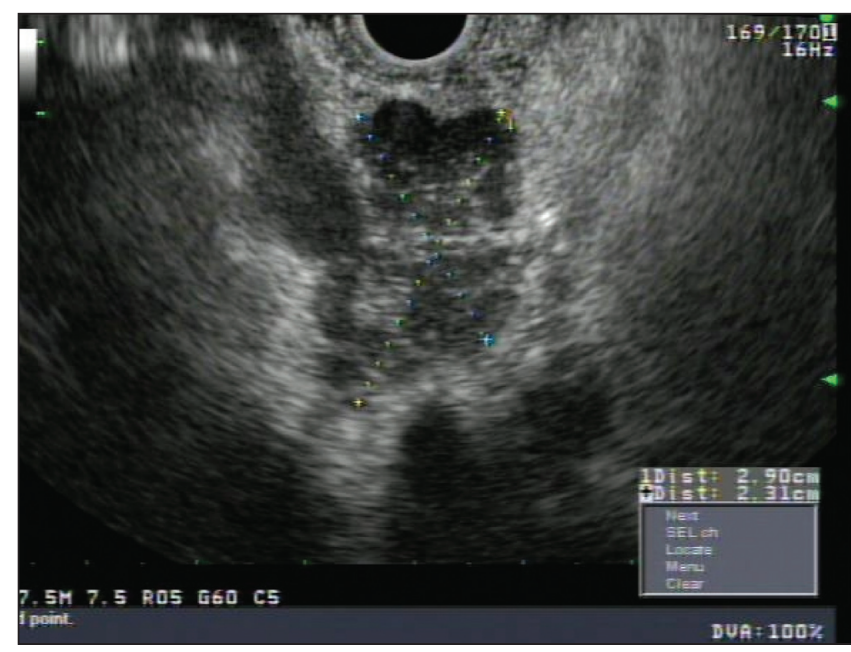

Figure 1) Linear endosonography showing a hypoechoic, heterogeneous, amorphous celiac lymph node $2.9 \mathrm{~cm} \times 2.3 \mathrm{~cm}$ in size

aspiration (FNA) (22 gauge Echotip ultra-endoscopic ultrasound needle, Wilson-Cook Medical Inc, USA) was performed (total of six passes) on the perigastric and celiac lymph nodes. Five millilitres of straw-coloured ascitic fluid was obtained for cytological examination by EUS-guided transgastric puncture. Although intrahepatic biliary dilation was noted, the diameter of the common bile duct $(6 \mathrm{~mm})$ was normal. The aspirate and cell block preparations from the lymph nodes showed metastatic adenocarcinomas that were positive for PSA and prostatespecific acid phosphatase, consistent with metastatic prostate adenocarcinoma (Figure 2). Rare aggregates of atypical cells with similar features were present within the ascites specimen. The patient was subsequently treated by androgen blockade with

${ }^{1}$ Division of Gastroenterology and Hepatology; ${ }^{2}$ Department of Pathology, Oregon Health and Science University, Portland, Oregon, USA

Correspondence: Dr Douglas O Faigel, Oregon Health and Science University, Physician's Pavilion, Suite 310, 3181 Southwest

Sam Jackson Park Road, Portland, Oregon 97239-3098, USA. Telephone 503-494-8577, fax 503-494-8776, e-mail faigeld@ohsu.edu

Received for publication May 11, 2008. Accepted May 23, 2008 


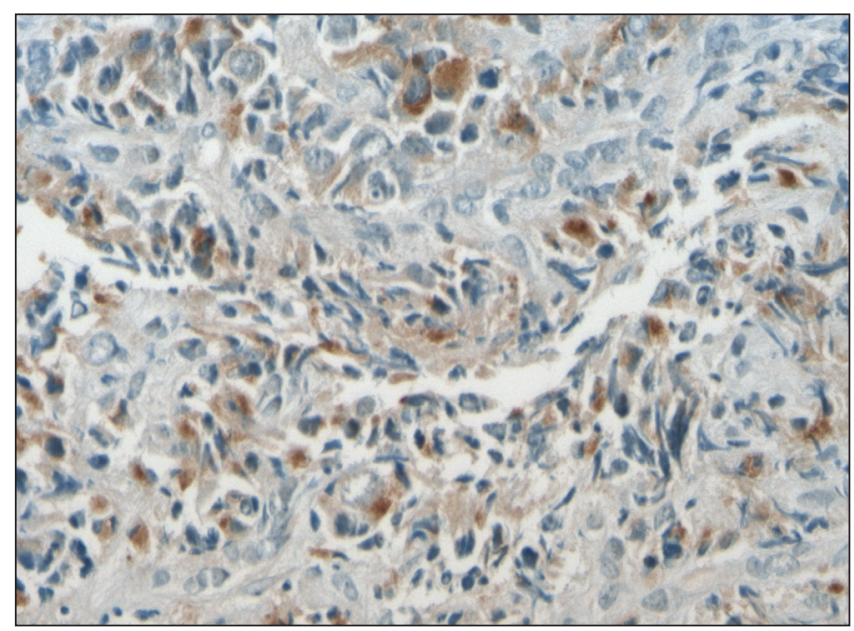

Figure 2) Immunohistochemical studies performed on the cell block show the atypical epithelial cells. Patchy, strong positivity for prostate-specific antigen and prostate-specific acid phospatase (brown in colour) is consistent with a metastatic adenocarcinoma of prostatic origin (original magnification $\times 200$ )

the leutenizing hormone-releasing hormone agonists leuprolide and bicalutamide. A CT scan four months after the initiation of androgen blockade therapy revealed a marked decrease in retroperitoneal/peripancreatic adenopathy and the persistence of ascites.

\section{DISCUSSION}

The role of EUS is well-established in gastrointestinal, pancreatobiliary, and lung cancer diagnosis and staging (1). Until the introduction of EUS-FNA, only lymph node echofeatures (ie, size greater than $1 \mathrm{~cm}$ ), echopoor appearance, distinct margins and round shape were used to predict malignant involvement

\section{REFERENCES}

1. LeBlanc JK, DeWitt J, Sherman S. Endoscopic ultrasound: How does it aid the surgeon? Adv Surg 2007;41:17-50.

2. Catalano MF, Sivak MV Jr, Rice T, Gragg LA, Van Dam J. Endosonographic features predictive of lymph node metastasis. Gastrointest Endosc 1994;40:442-6.

3. Bhutani MS, Hawes RH, Hoffman BJ. A comparison of the accuracy of echo features during endoscopic ultrasound (EUS) and EUS-guided fine-needle aspiration for diagnosis of malignant lymph node invasion. Gastrointest Endosc 1997;45:474-9.

4. Chen VK, Eloubeidi MA. Endoscopic ultrasound-guided fine-needle aspiration is superior to lymph node echofeatures: A prospective evaluation of mediastinal and peri-intestinal lymphadenopathy. Am J Gastroenterol 2004;99:628-33. of a lymph node (2). The accuracy of predicting malignant involvement of a lymph node is $80 \%$ when all four endosonographic criteria are present in a lymph node; however, only $25 \%$ of malignant lymph nodes have all four criteria (3). FNA allows for cytological evaluation of a lymph node. EUS-FNA has been found to be superior to lymph node echofeatures alone (4).

In the United States, adenocarcinoma of the prostate is the most common cause of cancer among men and the second most common cause of cancer mortality (5). Prostate cancer metastasizes hematogenously and/or lymphogeneously (6). With the measurement of PSA levels and the evaluation of asymptomatic men for prostate cancer, the incidence of lymph node metastasis has decreased from $40 \%$ to $10 \%$ (7). Prostate cancer usually metastasizes to regional lymph nodes. Despite the declining incidence of lymph node metastasis, the number of patients with positive lymph nodes is still significant.

The anatomical proximity of the prostate gland to the rectum allows for the use of EUS for locoregional staging of prostate cancer (8). EUS and EUS-FNA have rarely been used to detect distant prostate cancer metastases, with only a single report of EUS-FNA of mediastinal lymph nodes (9). To our knowledge, we describe the first use of EUS-FNA to detect metastatic prostate cancer from celiac and perigastric lymphadenopathy. Celiac lymph nodes, which are located within $2 \mathrm{~cm}$ of the origin of the celiac trunk, may be involved with malignant (esophageal, pancreatobiliary, lung cancer and lymphoma) as well as benign diseases (pancreatitis, infections, autoimmune hepatitis and sarcoidosis). Cytology with immunohistochemical staining of FNA samples for tumour markers allowed for the correct diagnosis in the present, unusual case of metastatic prostate cancer. We recommend routine sampling of abnormal-appearing lymph nodes as well as immunohistochemical staining to reach the correct diagnosis.

5. Jemal A, Siegel R, Ward E, Murray T, Xu J, Thun MJ. Cancer statistics, 2007. CA Cancer J Clin 2007;57:43-66.

6. Arya M, Bott SR, Shergill IS, Ahmed HU, Williamson M, Patel HR. The metastatic cascade in prostate cancer. Surg Oncol 2006;15:117-28.

7. Swanson GP, Thompson IM, Basler J. Current status of lymph node-positive prostate cancer: Incidence and predictors of outcome. Cancer 2006;107:439-50.

8. Artifon EL, Sakai P, Ishioka S, et al. EUS for locoregional staging of prostate cancer - a pilot study. Gastrointest Endosc 2007;65:440-7.

9 Perez NE, Maryala S, Seren S, Feng J, Pansare V, Dhar R. Metastatic prostate cancer presenting as mediastinal lymphadenopathy indentified by EUS with FNA. Gastrointest Endosc 2007;65:948-9. 


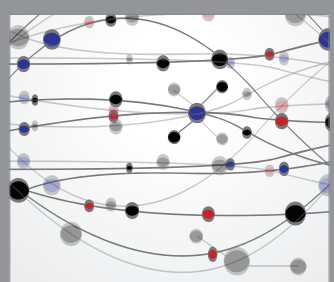

The Scientific World Journal
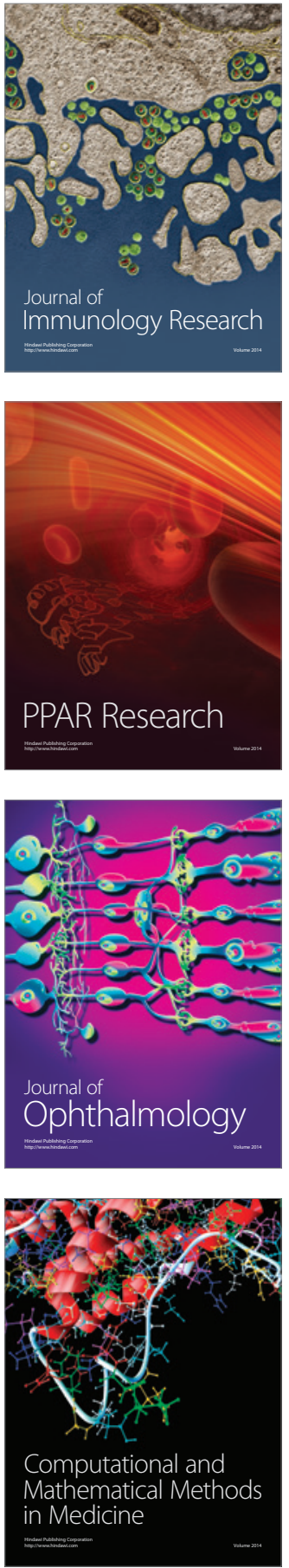

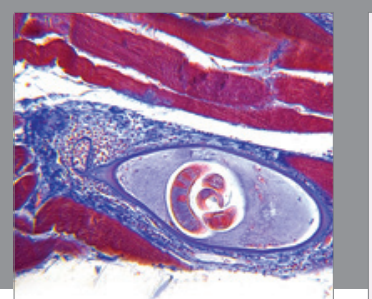

Gastroenterology Research and Practice

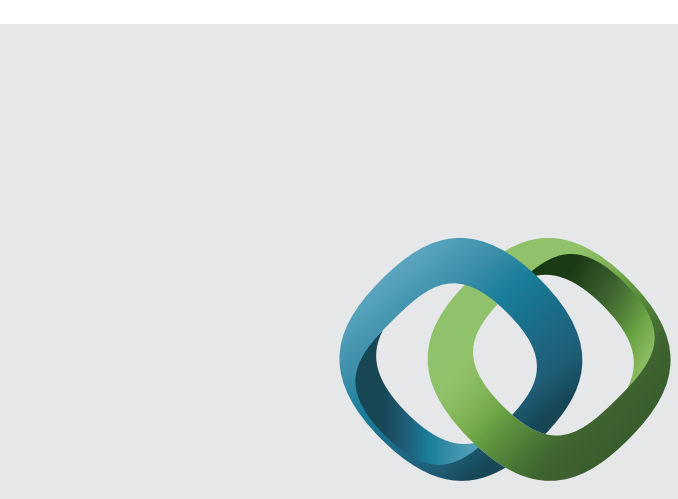

\section{Hindawi}

Submit your manuscripts at

http://www.hindawi.com
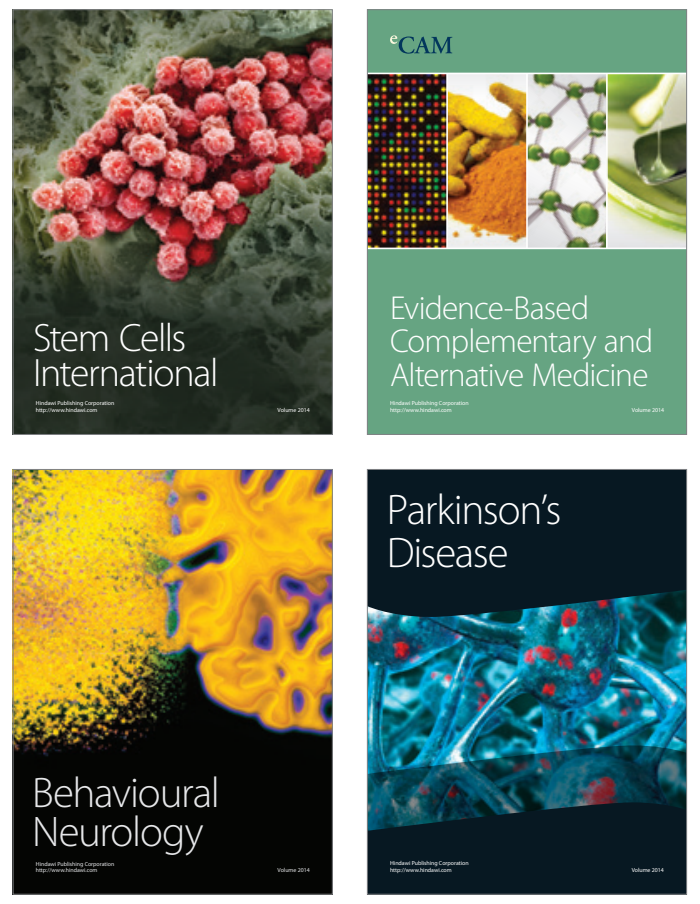
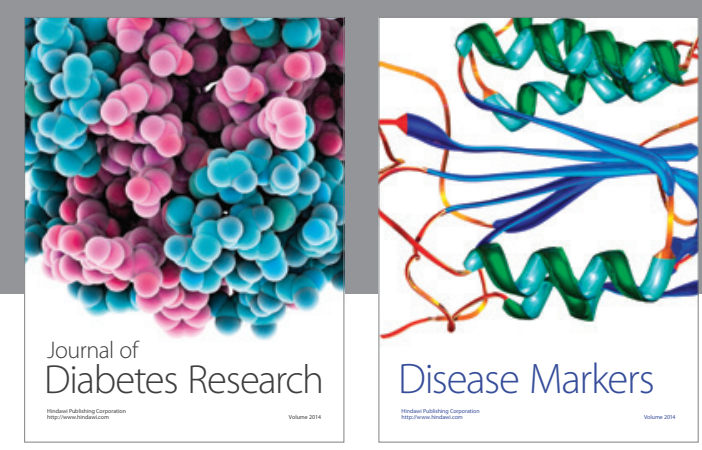

Disease Markers
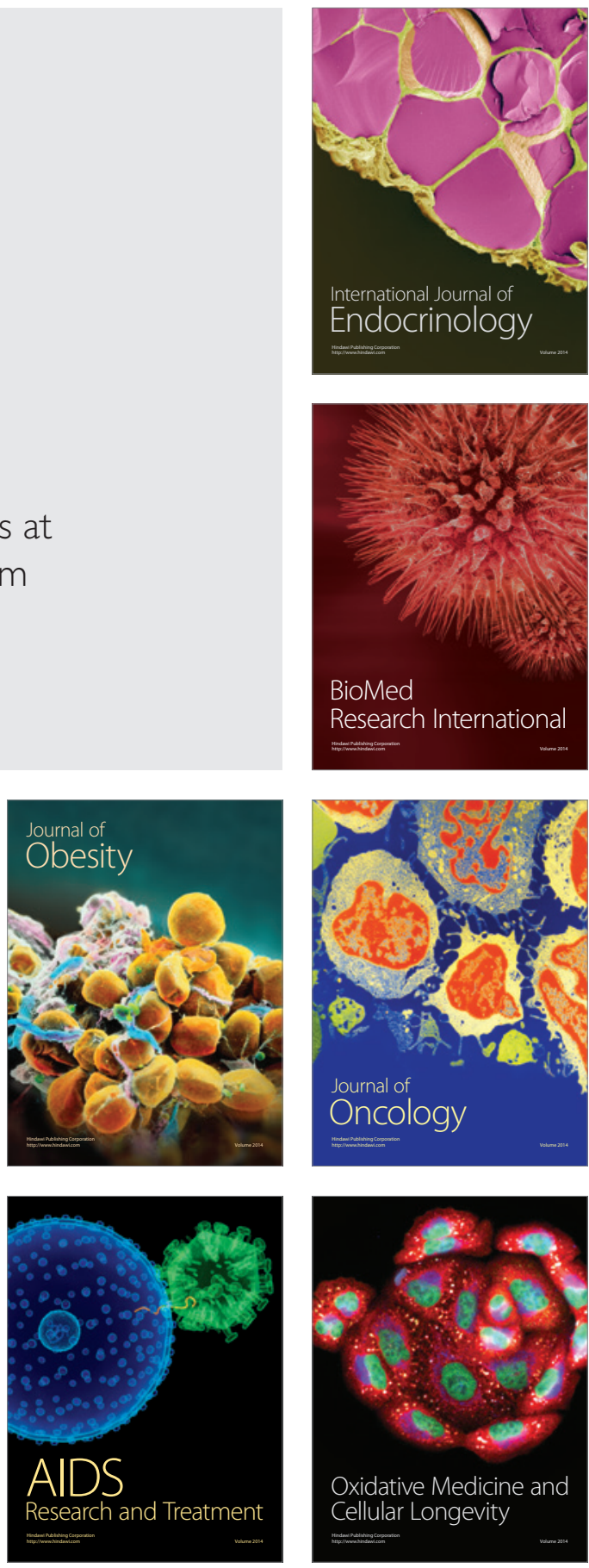